\title{
Biofilms as "Connectors" for Oral and Systems Medicine: A New Opportunity for Biomarkers, Molecular Targets, and Bacterial Eradication
}

\author{
Herman O. Sintim ${ }^{1,2}$ and Ulvi Kahraman Gürsoy ${ }^{3}$
}

\begin{abstract}
Oral health and systems medicine are intimately related but have remained, sadly, as isolated knowledge communities for decades. Are there veritable connector knowledge domains that can usefully link them together on the critical path to biomarker research and "one health"? In this context, it is noteworthy that bacteria form surfaceattached communities on most biological surfaces, including the oral cavity. Biofilm-forming bacteria contribute to periodontal diseases and recent evidences point to roles of these bacteria in systemic diseases as well, with cardiovascular diseases, obesity, and cancer as notable examples. Interestingly, the combined mass of microorganisms such as bacteria are so large that when we combine all plants and animals on earth, the total biomass of bacteria is still bigger. They literally do colonize everywhere, not only soil and water but our skin, digestive tract, and even oral cavity are colonized by bacteria. Hence efforts to delineate biofilm formation mechanisms of oral bacteria and microorganisms and the development of small molecules to inhibit biofilm formation in the oral cavity is very timely for both diagnostics and therapeutics. Research on biofilms can benefit both oral and systems medicine. Here, we examine, review, and synthesize new knowledge on the current understanding of oral biofilm formation, the small molecule targets that can inhibit biofilm formation in the mouth. We suggest new directions for both oral and systems medicine, using various omics technologies such as SILAC and RNAseq, that could yield deeper insights, biomarkers, and molecular targets to design small molecules that selectively aim at eradication of pathogenic oral bacteria. Ultimately, devising new ways to control and eradicate bacteria in biofilms will open up novel diagnostic and therapeutic avenues for oral and systemic diseases alike.
\end{abstract}

\section{Bacteria and Biofilms}

$\mathbf{M}$ ICROORGANISMS ARE ALL AROUND US. Their numbers are so large that when we combine all plants and animals on earth, the total biomass of bacteria is still bigger. They literally do colonize everywhere, not only soil and water but our skin, digestive tract, and even oral cavity are colonized by bacteria. Microbial communities can also impact responses to drugs and other xenobiotics (El Rakaiby et al., 2014).

As a matter of fact, the first observed bacteria by a microscope were from the oral cavity. It was a dental plaque that the father of microbiology, Anton van Leeuwenock, used as a specimen to observe bacteria under his first ever microscope. At first, when humans serendipitously learned about microorganisms, these small creatures were linked only with illness and disease. Today we know that bacteria contribute to homeostasis and regulation of human body, for example, by digesting indigestible molecules (such as nitrate) for us and converting them to useable products (such as nitrite) for us (Lundberg et al., 2008).

As stated, bacteria are everywhere, but are rarely found to be alone or floating freely (in planktonic forms). In water pipes, ships' hulls, soil, or even in the mouth of humans, bacteria prefer to bind on hard surfaces and form biofilms. Still, bacteria build biofilms only under distinctive situations, continuous sedimentation on a surface do not necessarily lead to biofilm formation (Seneviratne et al., 2012). Biofilms are sophisticated structures and to form biofilms bacteria adhere, multiply, secrete an extracellular polymeric matrix, and organize a three-dimensional community.

A typical biofilm consists of mono- or polymicrobial cells, polysaccharide, proteins, nucleic acids, and lipids (Flemming and Wingender, 2010). Biofilms are associated with nearly

\footnotetext{
${ }^{1}$ Department of Chemistry and Biochemistry, University of Maryland, College Park, Maryland.

${ }^{2}$ Department of Chemistry, Purdue University, West Lafayette, Indiana.

${ }^{3}$ Department of Periodontology, Institute of Dentistry, University of Turku, Turku, Finland.
}

(C) The Author(s) 2015; Published by Mary Ann Libert, Inc. This Open Access article is distributed under the terms of the Creative Commons License (http://creativecommons.org/licenses/by/4.0), which permits unrestricted use, distribution, and reproduction in any medium, provided the original work is properly credited. 
two third of all microbial infections in US (Potera, 1999), and should not be simply viewed or under estimated as "bacterial accumulations on surfaces".

\section{Oral Biofilms}

Oral biofilms carry similarities with environmental biofilms, but at the same time differ significantly. In the oral cavity, biofilms are composed of multispecies of bacteria, comprising of up to 700 different microbial species, and 100 to 200 of these species can be found in any healthy oral cavity (Kolenbrander et al., 2010). The composition of oral biofilms predominates with bacteria and extracellular matrix. Extracellular matrix is composed of deoxyribonucleic acid, proteins, polysaccharides, and lipids. Additionally, oral biofilms contain salivary glycoproteins, gingival crevicular fluid albumin, and host cell components.

Oral cavity is a nutrient rich, moist, warm environment, which is excellent for a bacterium to survive. However, there are also challenges; bacteria need to evade the flow of saliva, host antimicrobial proteins (defensins, cathelicidin, lactoferrin), variations in nutrient availabilities, $\mathrm{pH}$ changes, and antimicrobials, antiseptics, and antibiotics (Abiko and Saitoh, 2007). By being a part of a biofilm, bacteria become resistant to environmental stress and find necessary nutrients for growth and replicate much easily (Jakubovics and Kolenbrander, 2010).

Formation, development, and maturation of oral biofilms require bacterial colonization, interactions between bacterial cell surface adhesins and host receptors, chemical communication between bacteria, and production of extracellular matrix. Successful accumulation and multiplication of pathogenic bacteria in oral biofilms can lead to two common diseases, dental caries and periodontitis (Beikler and Flemmig, 2011). Furthermore, it is now understood that oral bacteria contribute to the initiation and/or progression of different types of cancers (Whitmore and Lamont, 2014). Hence, a clear understanding of interactions between different species of bacteria and between bacteria and the host could lead to new strategies for eliminating pathogenic biofilms and treating oral diseases.

\section{Supragingival and Subgingival Biofilms: Does the Localization Matter?}

Bacteria adhere to both soft and hard tissues in the oral cavity. Soft tissues, epithelial cells covering the oral mucosa, have rapid turnover rates. Thus, adhered bacteria cannot stay on this shedding surface long, and are removed together with dead epithelial cells. Teeth, on the other hand, have a nonshedding surface, and therefore, serve as an excellent binding surface for the bacteria. Supragingival biofilms are found above the gingival margin, typically characterized with Gram-positive aerobe communities. Subgingival biofilms, on the other hand, are primarily formed of Gram-negative anaerobes, and are localized under the gingival margin, between the gingiva and tooth surface.

The primary nutrient for supragingival biofilm bacteria is saliva. Bacteria in supragingival biofilms can degrade salivary components easily and efficiently. Gingival crevicular fluid is the primary nutrient source for bacteria in the subgingival biofilms (Jakubovics and Kolenbrander, 2010). It is generally true that supragingival biofilms form first and subgingival biofilms afterwards. However, when formed, subgingival biofilms demonstrate independent characteristics. The environment of subgingival biofilms is anaerobic, favoring the growth of mainly Gram-negative obligate anaerobes and restrict the growth of Gram-positive facultative aerobes. Moreover, removal of supragingival biofilm demonstrates only a minor effect on the composition of subgingival biofilms (Aruni et al., 2015).

\section{Oral Biofilms: A Symphony of Initial, Early, and Late Colonizers}

In the oral cavity, a well-cleaned tooth surface gets covered with a protein layer in just 2 hours. This layer is called acquired enamel pellicle and it contains up to 130 different salivary, serum, and cellular proteins (Dawes et al., 2015). Adhesion of bacteria to salivary pellicle is a milestone in formation of biofilms, because with this ability, bacteria form a resistance against shearing forces in the oral cavity (Rosan and Lamont, 2000).

Gram-positive aerobic bacteria, such as Actinomyces spp. and oral streptococci (Streptococcus intermedius, S. oralis) are the initial colonizers of the teeth surfaces. These bacteria interact with the pellicle-coated tooth surface and other bacteria as well. New bacterial adherence to immobilized bacteria is called co-adhesion, which is a form of coaggregation. Both co-aggregation and co-adhesion happens only between compatible organisms and requires cell surface adhesins and cognate receptors. (Kolenbrander et al., 2006). Streptococcal AGI/II proteins are good example of cellsurface molecules, which mediate co-aggregation between S. gordonii and A. oris (Egland et al., 2001). Actinomyces naeslundii adhere to proline-rich salivary proteins with its fimbriae, which also regulates its interbacterial binding (Yeung et al., 1999).

One major bacterial species to co-aggregate with early and late colonizers of oral biofilms is Fusobacterium nucleatum (Kolenbrander et al., 2010). F. nucleatum is a Gram-negative, anaerobic bacterium of the oral cavity, which acts as a bridge between early and late colonizers of the oral biofilms (Kolenbrander et al., 2010). Even though it is an anaerobic bacterium, it has tolerance to oxygen in biofilms (Gursoy et al., 2010). This ability allows $F$. nucleatum to support the growth of other strict anaerobes, Porphyromonas gingivalis, for example, in aerated environments (Diaz et al., 2002). Late colonizers of the oral biofilm are $P$. gingivalis, Aggregatibacter actinomycetemcomitans, Prevotella intermedia, Eubacterium spp., Tannerella forsythia, Selenomonas flueggei, and Treponema denticola (Fig. 1).

\section{Interbacterial Interactions in Oral Biofilm}

Bacterial behaviors in oral biofilms are complicated. In the biofilms, bacteria compete with each other, they help each other, but very importantly they communicate with each other. Communication of bacteria was for the first time described on marine bacteria, Vibrio fischeri. Oral bacteria use two different systems to communicate, competence signaling peptides can only be found in Gram-positive bacteria (Suntharalingam and Cvitkovitch, 2005), while autoinducer-2 (AI-2) can be found in both Gram-positives and Gram-negatives (Sun et al., 2004).

Studies in the culture media of $F$. nucleatum, $P$. gingivalis, and $P$. intermedia reported that several strains of these 


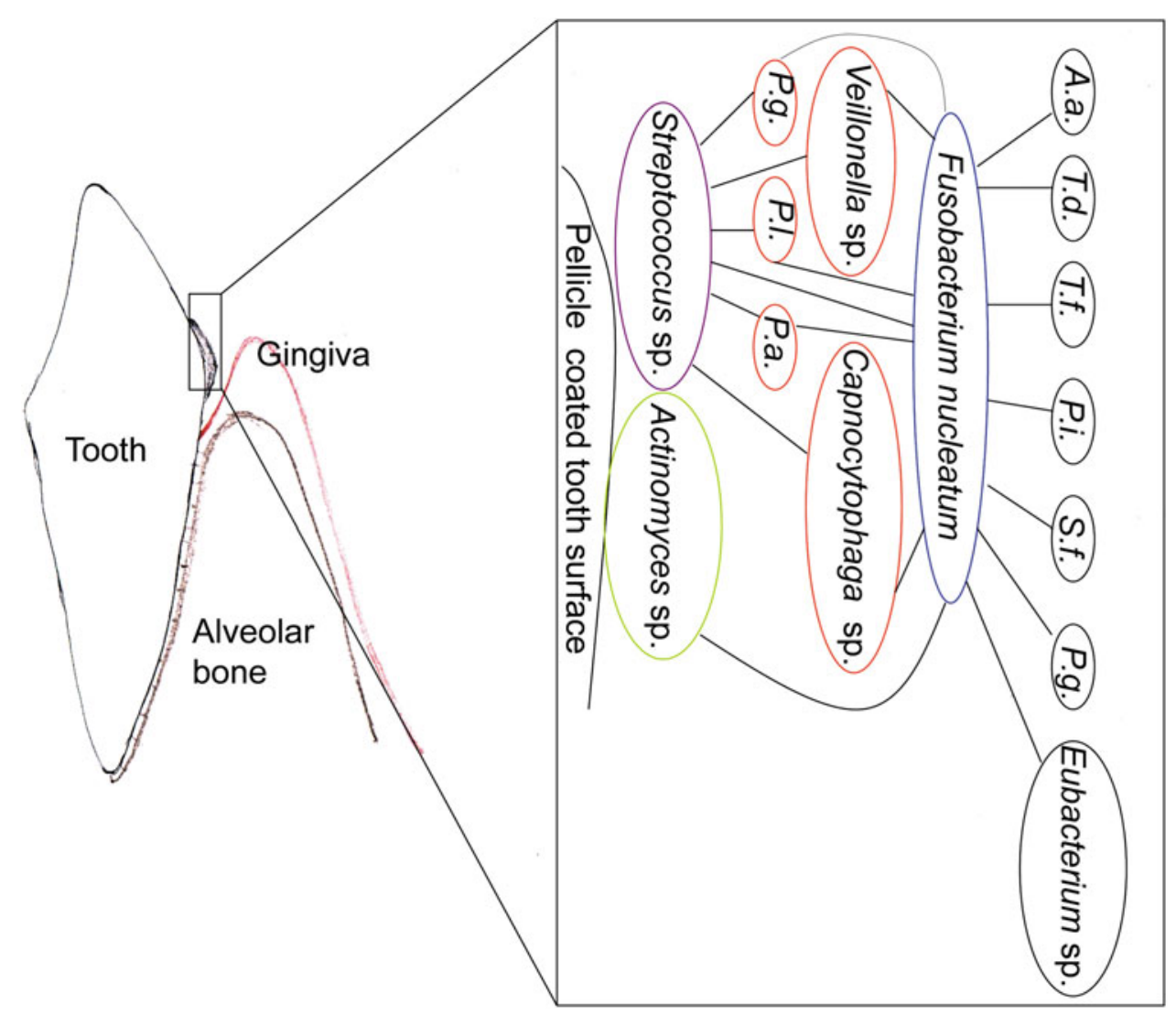

FIG. 1. Schematic description of oral biofilms, as described by Kolenbrander et al. (2010). (A.a.: Aggregatibacter actinomycetemcomitans, P.a.: Propionibacterium acnes, P.i.: Prevotella intermedia, P.g.: Porphyromonas gingivalis, P.l.: Prevotella loescheii, S.f.: Selenomonas flueggei, T.d.: Treponema denticola, T.f.: Tannerella forsythia).

bacteria produce AI-2 (Frias et al., 2001). Among the early colonizers, $S$. oralis 34 and $A$. naeslundii T14V also produce AI-2 (Rickard et al., 2008). Moreover, biofilm formation of A. actinomycetemcomitans is dependent of AI-2 signalling (Shao et al. 2007). Recent evidence suggested that bacterial molecules of communication not only regulates interbacterial communication, but also coordinate interactions of $P$. gingivalis with the host (Scheres et al., 2015).

Biofilms are sophisticated environments and carry evidence of mutualism and competition. A well-known example for the mutualism is the metabolic interaction between bacteria, however, exchange of signaling molecules and horizontal gene transfer also take part in it. A good example to mutualism is the interaction between oral streptococci, lactobacilli, A. actinomycetemcomitans, and veillonellae. Lactate, metabolic endproduct of streptococci and lactobacilli, can be utilized by A. actinomycetemcomitans. Presence of lactate in the growth media makes growth of $A$. actinomycetemcomitans faster and stronger (Brown and Whiteley, 2007; Jakubovics and Kolenbrander, 2010). Co-aggregations and cell-to-cell contacts of $P$. intermedia and $P$. nigrescens with $F$. nucleatum induce biofilm formation of these bacteria, however this finding is not dependent on AI-2 (Okuda et al., 2012).

$P$. gingivalis is an acid-sensitive bacterium and cannot grow in conditions with low $\mathrm{pH}$. $P$. intermedia and $F$. nucleatum produce ammonia and organic acid as metabolic outcomes, which lead to an increase in $\mathrm{pH}$ and provide a suitable growth condition to the acid-sensitive bacterium $P$. gingivalis (Takahashi et al., 2003). Cell-to-cell contact of bacteria is critical, autoaggregation of $F$. nucleatum in high cell numbers led to changes in expressions of at least 100 genes (Merritt et al., 2009).

Nevertheless, bacteria in biofilms do not only support each other, but also compete with each other. S. mutans and $S$. salivarius in the oral cavity produce antimicrobial peptides, bacteriocins, which can kill other bacteria (Hale et al., 2005). Additionally, oral streptococci produce hydrogen peroxide, which cause oxidative stress on strict anaerobes (Holmberg and Hallender, 1973).

\section{Disruption of Oral Bacteria Biofilms}

Three kinds of small molecules that inhibit biofilm formation by oral pathogens have been described. These are: i) inhibitors of cell-to-cell communication (quorum sensing, Fig. 2); ii) synthetic antibacterial agents that have both bactericidal and antibiofilm properties (Fig. 3); and iii) natural products, mainly isolated from food, leaves, and essential oils (Fig. 3), that either inhibit biofilm formation or disperse established biofilms.

\section{Inhibitors of Quorum Sensing}

AI-2 and CSP are the two QS autoinducers that have been thoroughly investigated as signaling molecules amongst oral 


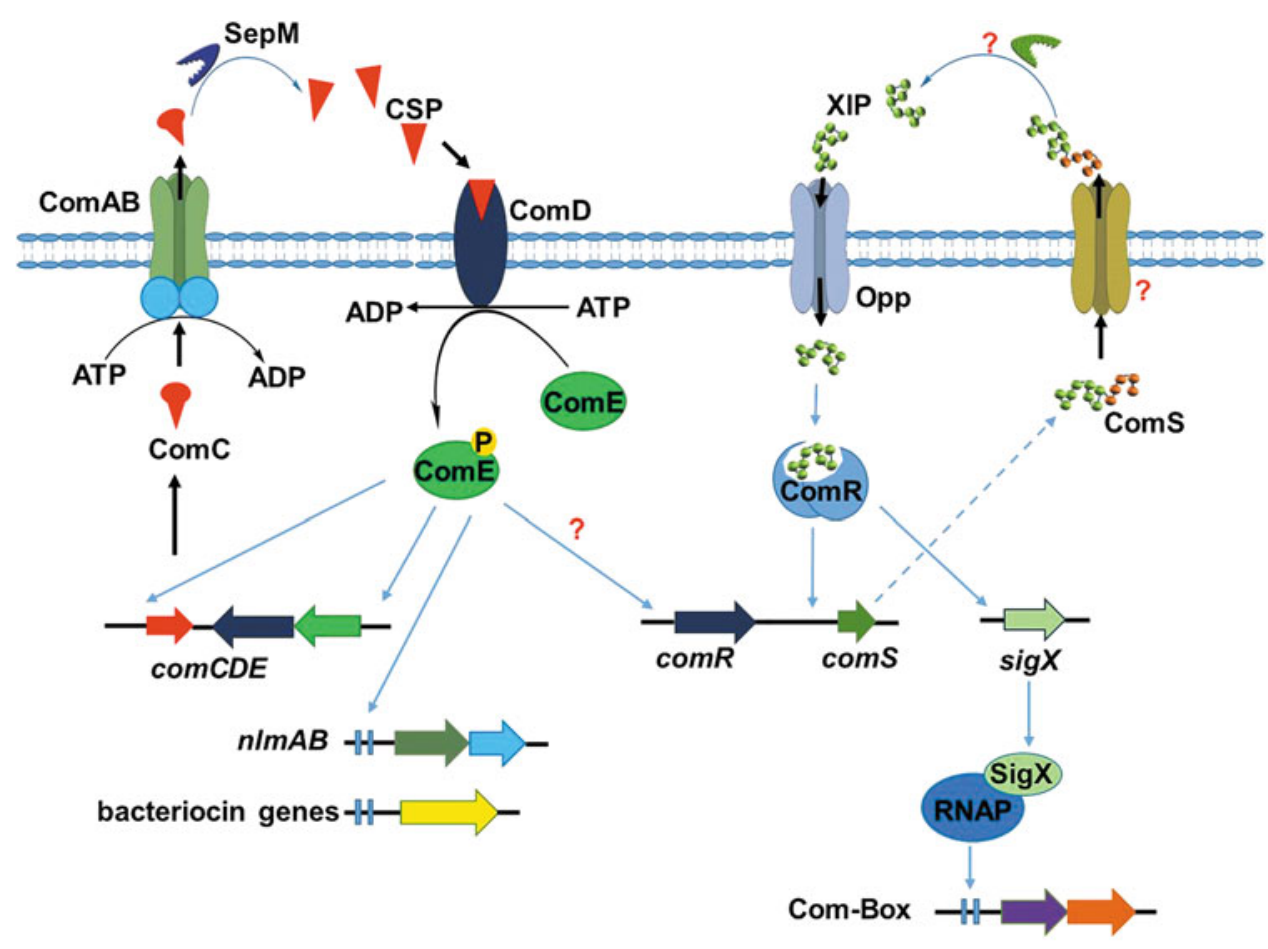

Late competence genes

FIG. 2. ComCDE and ComRS quorum-sensing regulatory systems in S. mutans. Both systems utilize peptides as autoinducers and modulate the production of bacteriocins and bacteriocin self-immunity proteins (ComCDE), biofilm formation, and competence.

bacteria, especially in $S$. mutans. The ComCDE (Li et al., 2001) and ComRS (Mashburn-Warren et al., 2010) systems, which utilize signaling peptides ComC signal peptide (CSP) and XIP, respectively, are the two major quorum-sensing systems in $S$. mutans. CSP-mediated signaling regulates DNA release, competence, bacteriocin production, stress response, and biofilm formation.

The biofilm mass produced by $S$. mutans, which did not produce CSP (comC mutant), was lower than that produced by wild-type $S$. mutans (Li et al., 2002), highlighting the importance of CSP signaling in biofilm formation by $S$. mutans. Interestingly, higher concentrations of CSP (i.e., concentrations that are higher than what is required for quorum sensing) have been shown to kill $S$. mutans (Qi et al., 2005). Many workers have investigated the antimicrobial and antibiofilm activities of various CSP analogs, and a few were found to either have antimicrobial or antibiofilm properties (LoVetri and Madhyastha, 2010; Petersen et al., 2006). For example, CSP analog, KBI-3221 (SGSLSTFFRLFNASFTQALGK) caused reduction in $S$. mutans biofilm mass (LoVetri and Madhyastha, 2010).

AI-2 is a so-called ubiquitous quorum sensing signal that is found in both Gram-negative and Gram-positive bacteria. AI-2 has been implicated in mutualistic biofilm formation between $S$. gordonii and $S$. oralis (Saenz et al., 2012) and also between $A$. naeslundii and $S$. oralis (Rickard et al.,

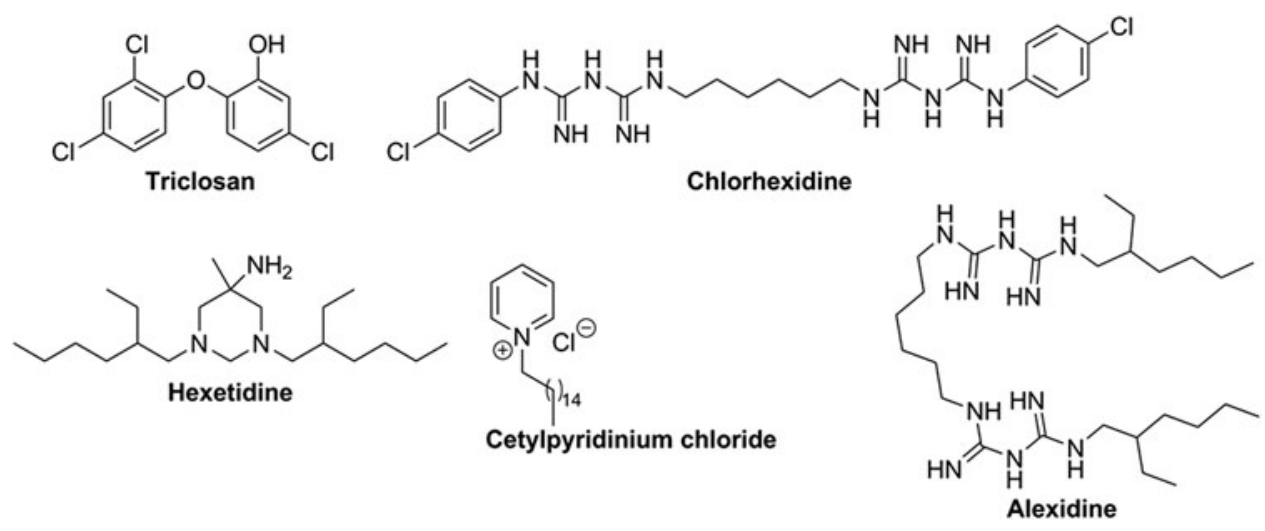

FIG. 3. Common molecules found in mouthwashes and toothpastes with antimicrobial and anti-biofilm properties. 
2006). AI-2 has also been implicated in biofilm formation by A. actinomycetemcomitans (Shao et al., 2007) or S. intermedius (Ahmed et al., 2008). Only a handful of small molecules that inhibit oral bacteria biofilm formation via the disruption of AI-2 signaling have been reported. AI-2 contributes to the co-aggregation of $F$. nucleatum with many bacteria. Interestingly, (5Z)-4-bromo-5-(bromomethylene)$2(5 \mathrm{H})$-furanone and D-ribose inhibited AI-2-induced biofilm growth and co-aggregation between $F$. nucleatum and various bacteria ( $P$. gingivalis, $T$. denticola, and $T$. forsythia) (Jang et al., 2013).

There are few examples of oral bacteria, such as $P$. gingivalis, which respond to $\mathrm{N}$-acyl homoserine lactones. Asahi et al. (2010) showed that analogs of AHL could reduce the thickness of biofilm formed by $P$. gingivalis. In another study, the same group demonstrated that AHL analogs synergistically enhanced the potencies of ofloxacin, cefuroxime, and minocycline against biofilms formed by $P$. gingivalis (Asahi et al., 2012).

\section{Antibacterial Agents That Have Both Bactericidal and Antibiofilm Properties Against Oral Pathogens}

Antimicrobial agents or antiseptics that are found in toothpastes and mouthwashes (see Fig. 3) include fluoride, triclosan, alexidine, chlorhexidine, hexetidine, benzalkonium chloride, and cetylpyridinium chloride. Fluoride's anticaries action is mainly derived from its role in remineralization, but some evidence also point to a direct antimicrobial effect of fluoride via the inhibition of bacterial metabolism (Marquis, 1995).

Triclosan is a fatty acid synthase inhibitor and found in several products, including soaps, body washes, toothpastes, and mouth rinses. Triclosan has antiplaque activity, and has been demonstrated to kill bacteria in oral biofilms (Marsh and Bradshaw, 1993). For example, Guggenheim et al. (2001) demonstrated that triclosan is active against supragingival plaque containing $A$. naeslundii, $V$. dispar, $F$. nucleatum, $S$. sobrinus, and $S$. oralis. Despite its wide use in hygiene products, there is accumulating evidence that triclosan alters hormone regulation in animals (Paul et al., 2013). In humans, elevated exposure to triclosan is associated with increased risk of obesity (Lankester et al., 2013).

Alexidine and chlorhexidine have antimicrobial activities against several oral bacteria. Both antimicrobial agents are active against $S$. mutans biofilm (Ruiz-Linares et al., 2014). Chlorhexidine affects metabolism in bacteria by promoting the leakage of metabolites from bacterial cells (Cheung et al., 2012; Iwami et al., 1995). Chlorhexidine has been used as an adjunct to primary periodontal and endodontic treatments for decades. Long-term use of chlorhexidine, however, is restricted due to discoloration of teeth and toxic effects on oral mucosa. Moreover, recent evidence on animal studies demonstrated that long-term disinfection of oral cavity with chlorhexidine impairs the nitrate-nitrite-nitric oxide balance, and eventually leads to high blood pressure (Hyde et al., 2014).

Hexetidine is a cationic antimicrobial agent that is active against both Gram-positive and Gram-negative bacteria. It is used in medicated mouth rinses, and has both antiplaque and antigingivitis properties (Sharma et al., 2003). Cationic ammonium compounds, benzalkonium chloride and cetylpyr- idinium chloride (Asadoorian and Williams, 2008), have antiseptic properties and have been shown to reduce oral biofilm, as well as reducing gingivitis. These ammonium compounds probably inhibit bacterial growth via the disruption of the bacterial membrane (McDonnell and Russell, 1999). The aforementioned compounds that are found in mouthwashes and toothpastes potently kill oral bacteria or reduce plaque formation, but concerns about safety (Jones, 1997), which is an ongoing debate, have spurred the search for other compounds from natural sources that may have a more desirable toxicity profile.

\section{Other Small Molecules, Mainly from Natural Sources, that Either Inhibit Biofilm Formation or Disperse Established Biofilms}

S. mutans is one of the major cariogenic bacteria, and the molecular details underlying how this bacteria attach to surfaces is now well understood. Glucosyltransferases (GTFB, GTFC, and GTFD) secreted by $S$. mutans catalyzes the formation of glucans, which attach to surfaces, via the polymerization of glycosyl units from carbohydrates (Tsumori and Kuramitsu, 1997). The bacteria then uses surface proteins, GbpA (Russell, 1979), GbpB (Smith et al., 1994), GbpC (Sato et al., 1997), and GbpD (Russell, 1979), which bind to the glucans, to adhere to surfaces. This is termed the sucrose-dependent pathway and is responsible for plaque formation.

Natural products, such as polyphenols that are found in trees, are known inhibitors of $S$. mutans glucosyltransferases (Nakahara et al., 1993) and have shown antibiofilm activities against oral biofilms, vide infra. Several other phenols (Fig. 4) also inhibit the biofilms of S. mutans and other oral bacteria but via poorly defined mechansims.

Macelignan, at $10 \mu \mathrm{g} / \mathrm{mL}$, reduced single primary biofilms of $S$. mutans, S. sanguis, and A. viscosus by $50 \%$ when applied for $30 \mathrm{~min}$ (Yanti et al., 2008). Panduratin and isopanduratin have potent activities against several oral bacteria, and inhibited formation of multispecies oral biofilm consisting of S. mutans, S. sanguis, and A. viscosus (Yanti et al., 2009). Hydroxychavicol is efficacious against adherent S. mutans in the presence of sucrose (Sharma et al., 2009). Xanthorrhizol (XTZ), which is found in the rhizome of Curcuma xanthorrhiza Roxb., was found to differentially affect the biofilm of $S$. mutans at different phases of growth. Whereas $5 \mu \mathrm{M}$ of XTZ completely inhibited $S$. mutans biofilm at the adherent phase of growth, up to $50 \mu \mathrm{M}$ of XTZ dispersed $76 \%$ of $S$. mutans biofilm at the plateau accumulated phase (Rukayadi and Hwang, 2006).

A fraction containing resveratrol, emodin, and physcion, obtained from the plant Polygonum cuspidatum, reduced the production of water-insoluble polysaccharides by $S$. mutans (Pandit et al., 2012). Gallic acid and methyl gallate inhibited the in vitro formation of $\mathrm{S}$. mutans biofilm, albeit at high concentrations $(1 \mathrm{mg} / \mathrm{mL}$ for gallic acid and $4 \mathrm{mg} / \mathrm{mL}$ for methyl gallate) (Kang et al., 2008). Ellagic acid inhibited the formation of water-insoluble glucan generated by $S$. mutans (Loo et al., 2010).

Thymol, found in in oil of thyme, has antiplaque activity but it is more effective when used in combination with chlorhexidine digluconate (Filoche et al., 2005). Carvacrol is a phenol isomer of thymol, and it demonstrates strong 


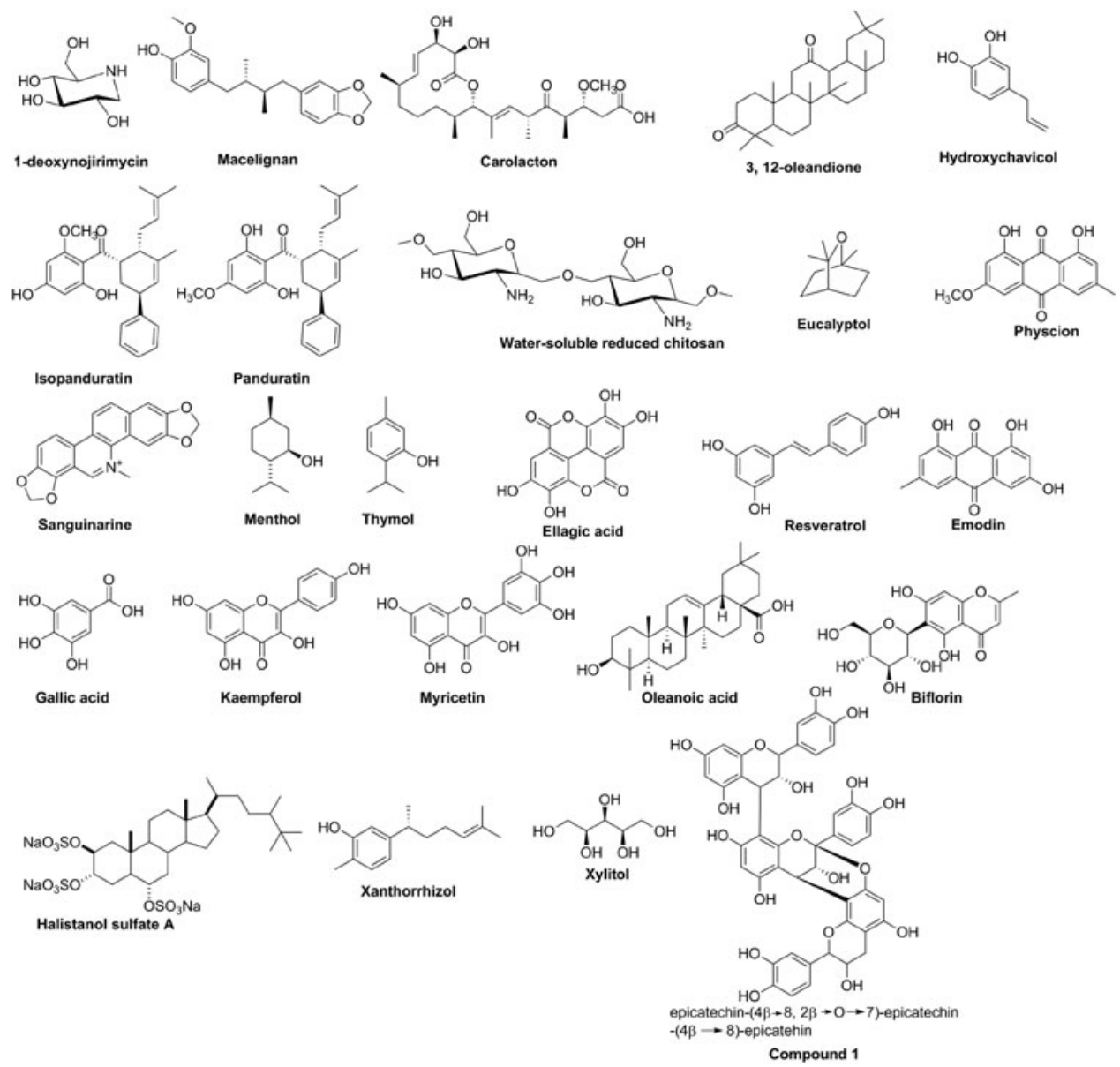

FIG. 4. Natural products with anti-biofilm properties.

antibacterial and antibiofilm on periodontal pathogens, and antiapoptotic effects on epithelial cells (Zeidan-Chulia et al., 2014). Flavonoids such as kaempferol, myricetin, and biflorin, and proanthocyanidins (such as compound 1, see Fig. 4), commonly found in cranberry fruit, inhibited surface-adsorbed glucosyltransferases and acid production by $S$. mutans cells (Duarte et al., 2006).

In addition to the aforementioned phenolic compounds, other nonphenolic small molecules such as 1-deoxynojirimycin (Islam et al., 2008), carolacton (Kunze et al., 2010), 3,12oleandione (Murugan et al., 2013), water-soluble reduced chitosan (Bae et al., 2006), eucalyptol and menthol (Chung et al., 2006), sanguinarine (Hannah et al., 1989), oleanoic acid (Kozai et al., 1987), xylitol (Loesche et al., 1984), and halistanol sulfate A (Lima et al., 2014) have all been shown to possess anti-caries properties.

Many of the natural phenolic compounds, including the flavonoids, tannins, coumarins, lignans, stilbenes, and quinones have long been in use in treatment of dental and medical diseases. Nevertheless, there are some issues that limit their common use. Majority of these compounds are volatile, meaning that their residual effect is short-lived. Second, these compounds require a solvent such as alcohol (or propylene glycol in non-alcohol formulas) to homogenously dissolve in oral health care product. These solvents bring additional problems, such as being risk factor of oral cancers. Finally, in animal studies it is observed that several phenolic compounds have neurotoxic and hepatotoxic effects (Ellse and Wall, 2014).

\section{Role of OMICS in Development of Next-Generation Anti-Infectious Agents}

Despite many years of intensive research to find small molecules that can selectively target pathogenic oral bacteria without affecting commensal bacteria, there is no drug in use today that achieves selective targeting. The different OMICS technologies, especially the newer and powerful ones that can be used on large systems, could help identify targets that are critical for pathogenicity. For example, with the use of Stable Isotope Labeling by Amino Acids in Cell Culture (SILAC)based quantitative proteomics (SILAQ) or other relative proteomics quantitation methods such as isotope-coded affinity tags (ICAT), isobaric tags for relative and absolute quantitation (iTRAQ), or metal-coded tags (MeCAT), it could be possible to identify proteins that are overexpressed in pathogenic but not commensal oral bacteria. Some of these proteins may end up being critical for periodontal disease or caries formation.

Analogously, RNA profiling of pathogenic oral bacteria at various stages of plaque formation could yield valuable insights into which gene products should be targeted for antiinfection therapy. Finally, great advances have been made to improve the sensitivity of mass spectrometry instruments, 
and this has now permitted the identification of small molecules in complex biological environments, and in the presence of hundreds of other small molecules. Hence the stage is set to use these sophisticated metabolomic approaches to discover novel signaling molecules that mediate bacteria perseverance. Targeting the signaling systems that use such signaling molecules could lead to new generation anti-caries agents that do not target commensal oral pathogens.

\section{Conclusions and Future Outlook}

In the last two decades, many molecular details that underpin the co-aggregation and/or biofilm formation of oral bacteria have been well elucidated (Rabin et al., 2015a). Many of the enzymes that promote the formation of waterinsoluble glucan matrices, as well as enzymes that facilitate acid tolerance by cariogenic bacteria, have been well characterized. The stage is therefore set to develop small molecules to inhibit these important enzymes that are involved in caries formation.

On the other hand, although many molecules that are commonly found in plants and food, oxidizing agents (Wennström and Lindhe, 1979), synthetic compounds such as salifluor (Coburn et al., 1981; Furuichi et al., 1996), and metals (Ingram et al., 1992; Waaler and Rölla, 1980) have been shown to inhibit biofilm formation by many oral bacteria, the molecular targets of these molecules have not been characterized (Rabin et al., 2015b). Again, we believe that omics will play an important role in unraveling the targets of many antimicrobial agents that have shown activity against oral pathogens (Bowler et al., 2013; Karaosmanoglu et al., 2014).

The veritable links between oral health and systems medicine, as noted in this review article, should ultimately help to cultivate new and sustainable innovation ecosystems in the field of omics sciences (Dandara et al., 2014). We think connecting the dots between these two knowledge domains is long overdue and the present special issue shall greatly remedy these gaps in omics scholarship.

\section{Acknowledgments}

This work was supported by grants from the National Science Foundation 1307218 and 1264509.

\section{Author Disclosure Statement}

The authors declare that there are no conflicting financial interests.

\section{References}

Abiko Y, and Saitoh M. (2007). Salivary defensins and their importance in oral health and disease. Curr Pharm Des 13, 3065-3072.

Aruni AW, Dou Y, Mishra A, and Fletcher HM. (2015). The biofilm community-Rebels with a cause. Curr Oral Health Rep 2, 48-56.

Asadoorian J, and Williams K. (2008). Cetylpyridinium chloride mouth rinse on gingivitis and plaque. J Dent Hyg 82, 1-5.

Asahi Y, Noiri Y, Igarashi J, Asai H, Suga H, and Ebisu S. (2010). Effects of $\mathrm{N}$-acyl homoserine lactone analogues on Porphyromonas gingivalis biofilm formation. J Periodont Res 45, 25599261.
Asahi Y, Noiri Y, Igarashi J, Suga H, Azakami H, and Ebisu S. (2012). Synergistic effects of antibiotics and an N-acyl homoserine lactone analog on Porphyromonas gingivalis biofilms. J Appl Microbiol 112, 404-411.

Bae K, Jun EJ, Lee SM, Paik DI, and Kim JB. (2006). Effect of water-soluble reduced chitosan on Streptococcus mutans, plaque regrowth and biofilm vitality. Clin Oral Investig 10, 102-107.

Beikler T, and Flemmig TF. (2011). Oral biofilm-associated diseases: Trends and implications for quality of life, systemic health and expenditures. Periodontol 2000 55, 87-103.

Bowler RP, Bahr TM, Hughes G, Lutz S, Kim YI, Coldren CD, Reisdorph N, and Kechris KJ. (2013). Integrative omics approach identifies interleukin-16 as a biomarker of emphysema. OMICS 17, 619-626.

Brown SA, and Whiteley M. (2007). A novel exclusion mechanism for carbon resource partitioning in Aggregatibacter actinomycetemcomitans. J Bacteriol 189, 6407-6414.

Cheung HY, Wong MM, Cheung SH, Liang LY, Lam YW, and Chiu SK. (2012). Differential actions of chlorhexidine on the cell wall of Bacillus subtilis and Escherichia coli. PLoS One 7, e36659.

Chung JY, Choo JH, Lee MH, and Hwang JK. (2006). Anticariogenic activity of macelignan isolated from Myristica fragrans (nutmeg) against Streptococcus mutans. Phytomedicine 13, 261-266.

Coburn RA, Batista AJ, Evans RT, and Genco RJ. (1981). Potential alicylamide antiplaque agents. In vitro antibacterial activity against Actinomyces viscosus. J Med Chem 24, 1245-1249.

Dandara C, Huzair F, Borda-Rodriguez A, et al. (2014). H3Africa and the African life sciences ecosystem: Building sustainable innovation. OMICS 18, 733-739.

Dawes C, Pedersen AM, Villa A, et al. (2015). The functions of human saliva: A review sponsored by the World Workshop on Oral Medicine VI. Arch Oral Biol 60, 863-874.

Diaz PI, Zilm PS, and Rogers AH. (2002). Fusobacterium nucleatum supports the growth of Porphyromonas gingivalis in oxygenated and carbon-dioxide-depleted environments. Microbiology 148, 467-472.

Duarte S, Gregoire S, Singh AP, et al. (2006). Inhibitory effects of cranberry polyphenols on formation and acidogenicity of Streptococcus mutans biofilms. FEMS Microbiol Lett 257, 50-56.

Egland PG, Dû LD, and Kolenbrander PE. (2001). Identification of independent Streptococcus gordonii SspA and SspB functions in coaggregation with Actinomyces naeslundii. Infect Immun 69, 7512-7516.

ElRakaiby M, Dutilh BE, Rizkallah MR, Boleij A, Cole JN, and Aziz RK. (2014). Pharmacomicrobiomics: The impact of human microbiome variations on systems pharmacology and personalized therapeutics. OMICS 18, 402-414.

Ellse L, and Wall R. (2014). The use of essential oils in veterinary ectoparasite control: A review. Med Vet Entomol 28, 233-243.

Filoche SK, Soma K, and Sissons CH. (2005). Antimicrobial effects of essential oils in combination with chlorhexidine digluconate. Oral Microbiol Immunol 20, 221-225.

Flemming HC, and Wingender J. (2010). The biofilm matrix. Nat Rev Microbiol 8, 623-633.

Frias J, Olle E, and Alsina M. (2001). Periodontal pathogens produce quorum sensing signal molecules. Infect Immun 69, 3431-3434.

Furuichi Y, Ramberg P, Lindhe J, Nabi N, and Gaffar A. (1996). Some effects of mouthrinses containing salifluor on 
de novo plaque formation and developing gingivitis. $\mathrm{J}$ Clin Periodont 23, 795-802.

Guggenheim B, Giertsen E, Schupbach P, and Shapiro S. (2001). Validation of an in vitro biofilm model of supragingival plaque. J Dent Res 80, 363-370.

Gursoy UK, Pöllänen M, Könönen E, and Uitto VJ. (2010). Biofilm formation enhances the oxygen tolerance and invasiveness of Fusobacterium nucleatum in an oral mucosa culture model. J Periodontol 81, 1084-1091.

Hale JD, Ting YT, Jack RW, Tagg JR, and Heng NC. (2005). Bacteriocin (mutacin) production by Streptococcus mutans genome sequence reference strain UA159: Elucidation of the antimicrobial repertoire by genetic dissection. Appl Environ Microbiol 71, 7613-7617.

Hannah JJ, Johnson JD, and Kuftinee MM. (1989). Long-term evaluation of toothpaste and oral rinse containing sanguinaria extract in controlling plaque and gingival inflammation and sulcular bleeding during orthodontic treatment. Am J Orthod Maxillofac Orthopaed 96, 199-207.

Holmberg K, and Hallander HO. (1973). Production of bactericidal concentrations of hydrogen peroxide by Streptococcus sanguis. Arch Oral Biol 18, 423-434.

Hyde ER, Luk B, Cron S, et al. (2014). Characterization of the rat oral microbiome and the effects of dietary nitrate. Free Radic Biol Med 77, 249-257.

Ingram GS, Horay CP, and Stead WJ. (1992). Interaction of zinc with dental mineral. Caries Res 26, 248-253.

Islam B, Khan SN, Haque I, Alam M, Mushfiq M, and Khan AU. (2008). Novel anti-adherence activity of mulberry leaves: Inhibition of Streptococcus mutans biofilm by 1-deoxynojirimycin isolated from Morus alba. J Antimicrob Chemother 62, 751-757.

Iwami Y, Schachtele CF, and Yamada T. (1995). Mechanism of inhibition of glycolysis in Streptococcus mutans NCIB 11723 by chlorhexidine. Oral Microbiol Immunol 10, 360-364.

Jang YJ, Choi YJ, Lee SH, Jun HK, and Choi BK. (2013). Autoinducer 2 of Fusobacterium nucleatum as a target molecule to inhibit biofilm formation of periodontopathogens. Arch Oral Biol 58, 17-27.

Jakubovics NS, and Kolenbrander PE. (2010). The road to ruin: The formation of disease-associated oral biofilms. Oral Dis 16, 729-739.

Jones CG. (1997). Chlorhexidine: Is it still the gold standard? Periodontol 2000 15, 55-56.

Kang MS, Oh JS, Kang IC, Hong SJ, and Choi CH. (2008). Inhibitory effect of methyl gallate and gallic acid on oral bacteria. J Microbiol 46, 744-750.

Karaosmanoglu K, Sayar NA, Kurnaz IA, and Akbulut BS. (2014). Assessment of berberine as a multi-target antimicrobial: A multi-omics study for drug discovery and repositioning. OMICS 18, 42-53.

Kolenbrander PE, Palmer RJ Jr, Rickard AH, Jakubovics NS, Chalmers NI, and Diaz PI. (2006). Bacterial interactions and successions during plaque development. Periodontol 200042 , 47-79.

Kolenbrander PE, Palmer RJ Jr, Periasamy S, and Jakubovics NS. (2010). Oral multispecies biofilm development and the key role of cell-cell distance. Nat Rev Microbiol 8, 471-480.

Könönen E, and Wade WG. (2015). Actinomyces and related organisms in human infections. Clin Microbiol Rev 28, 419-442.

Kozai K, Miyake Y, Kohda H, et al. (1987). Inhibition of glucosyltransferase from Streptococcus mutans by oleanolic acid and ursolic acid. Caries Res 21, 104-108.
Kunze B, Reck M, Dötsch A, et al. (2010). Damage of Streptococcus mutans biofilms by carolacton, a secondary metabolite from the myxobacterium Sorangium cellulosum. BMC Microbiol 10, 199.

Lankester J, Patel C, Cullen MR, Ley C, and Parsonnet J. (2013). Urinary triclosan is associated with elevated body mass index in NHANES. PLoS One 8, e80057.

Li YH, Lau PC, Lee JH, Ellen RP, and Cvitkovitch DG. (2001). Natural genetic transformation of Streptococcus mutans growing in biofilms. J Bacteriol 183, 897-908.

Li YH, Tang N, Aspiras MB, et al. (2002). A quorum-sensing signaling system essential for genetic competence in Streptococcus mutans is involved in biofilm formation. J Bacteriol 184, 2699-2708.

Lima BA, de Lira SP, Kossuga MH, Gonçalves RB, Berlinck RGS, and Kamiyaf RU. (2014). Halistanol sulfate A and rodriguesines A and B are antimicrobial and antibiofilm agents against the cariogenic bacterium Streptococcus mutans. Rev Bras Farmacogn 24, 651-659.

Loesche WJ, Grossman NS, Earnest R, and Corpron R. (1984). The effect of chewing xylitol gum on the plaque and saliva levels of Streptococcus mutans. J Am Dent Assoc 108, 587-592.

Loo WTY, Jin LJ, Cheung MNB, and Chow LWC. (2010). Evaluation of ellagic acid on the activities of oral bacteria with the use of adenosine triphosphate (ATP) bioluminescence assay. Afr J Biotechnol 9, 3938-3943.

LoVetri K, and Madhyastha S. (2010). Antimicrobial and antibiofilm activity of quorum sensing peptides and peptide analogues against oral biofilm bacteria. Methods Mol Biol 618, 383-392.

Lundberg JO, Weitzberg E, and Gladwin MT. (2008). The nitrate-nitrite-nitric oxide pathway in physiology and therapeutics. Nat Rev Drug Discov 7, 156-167.

Marquis RE. Antimicrobial actions of fluoride for oral bacteria. Can J Microbiol 1995, 41, 955-964.

Marsh PD, and Bradshaw DJ. (1993). Microbiological effects of new agents in dentifrices for plaque control. Int Dent $\mathbf{J} 43$, 399-406.

Mashburn-Warren L, Morrison DA, and Federle MJ. (2010). A novel double-tryptophan peptide pheromone is conserved in mutans and pyogenic Streptococci and controls competence in Streptococcus mutans via an Rgg regulator. Mol Microbiol 78, 589-606.

McDonnell G, and Russell AD. (1999). Antiseptics and disinfectants: Activity, action, and resistance. Clin Microbiol Rev 12, 147-179.

Merritt J, Niu G, Okinaga T, and Qi F. (2009). Autoaggregation response of Fusobacterium nucleatum. Appl Environ Microbiol 75, 7725-7733.

Murugan K, Sekar K, Sangeetha S, Ranjitha S, and Sohaibani SA. (2013). Antibiofilm and quorum sensing inhibitory activity of Achyranthes aspera on cariogenic Streptococcus mutans: An in vitro and in silico study. Pharm Biol 51, 728-736.

Nakahara K, Kawabata S, Ono H, et al. (1993). Inhibitory effect of oolong tea polyphenols on glycosyltransferases of mutans Streptococci. Appl Environ Microbiol 59, 968-973.

Okuda T, Kokubu E, Kawana T, Saito A, Okuda K, and Ishihara K. (2012). Synergy in biofilm formation between Fusobacterium nucleatum and Prevotella species. Anaerobe 18, 110-116.

Pandit S, Kim HJ, Park SH, and Jeon JG. (2012). Enhancement of fluoride activity against Streptococcus mutans biofilms by 
a substance separated from Polygonum cuspidatum. Biofouling 28, 279-287.

Paul KB, Thompson JT, Simmons SO, Vanden Heuvel JP, and Crofton KM. (2013). Evidence for triclosan-induced activation of human and rodent xenobiotic nuclear receptors. Toxicol In Vitro 27, 2049-2060.

Petersen FC, Fimland G, and Scheie AA. (2006). Purification and functional studies of a potent modified quorum-sensing peptide and a two-peptide bacteriocin in Streptococcus mutans. Mol Microbiol 61, 1322-1334.

Potera C. (1999). Forging a link between biofilms and disease. Science 283, 1839.

Qi F, Kreth J, Lévesque CM, et al. (2005). Peptide pheromone induced cell death of Streptococcus mutans. FEMS Microbiol Lett 25, 321-326.

Rabin N, Zheng Y, Opoku-Temeng C, Du Y, Bonsu E, and Sintim HO. (2015a). Biofilm formation mechanisms and targets for developing anti-biofilm agents. Future Med Chem 7, 493-512.

Rabin N, Zheng Y, Opoku-Temeng C, Du Y, Bonsu E, and Sintim HO. (2015b). Agents that inhibit bacterial biofilm formation. Future Med Chem 7, 647-671.

Rickard AH, Campagna SR, and Kolenbrander PE. (2008). Autoinducer- 2 is produced in saliva-fed flow conditions relevant to natural oral biofilms. J Appl Microbiol 105, 2096-2103.

Rickard AH, Palmer RJ Jr, Blehert DS, et al. (2006). Autoinducer 2: A concentration-dependent signal for mutualistic bacterial biofilm growth. Mol Microbiol 60, 1446-1456.

Rosan B, and Lamont RJ. (2000). Dental plaque formation. Microbes Infect 2, 1599-1607.

Ruiz-Linares M, Ferrer-Luque CM, Arias-Moliz T, de Castro P, Aguado B, and Baca P. (2014). Antimicrobial activity of alexidine, chlorhexidine and cetrimide against Streptococcus mutans biofilm. Ann Clin Microbiol Antimicrob 13, 41.

Rukayadi Y, and Hwang JK. (2006). In vitro activity of xanthorrhizol against Streptococcus mutans biofilms. Lett Appl Microbiol 42, 400-404.

Russell RR. (1979). Glucan-binding proteins of Streptococcus mutans serotype c. J Gen Microbiol 112, 197-201.

Saenz GC, Rao D, Underwood A, et al. (2012). Autoinducer-2 influences interactions amongst pioneer colonizing streptococci in oral biofilms. Microbiol 158, 1783-1795.

Sato Y, Yamamoto Y, and Kizaki H. (1997). Cloning and sequence analysis of the gbpC gene encoding a novel glucan-binding protein of Streptococcus mutans. Infect Immun 65, 668-675.

Scheres N, Lamont RJ, Crielaard W, and Krom BP. (2015). LuxS signaling in Porphyromonas gingivalis-host interactions. Anaerobe 35, 3-9.

Seneviratne CJ, Wang Y, Jin L, Wong SS, Herath TD, and Samaranayake LP. (2012). Unraveling the resistance of microbial biofilms: Has proteomics been helpful? Proteomics $12,651-665$.

Shao H, Lamont RJ, and Demuth DR. (2007). Autoinducer 2 is required for biofilm growth of Aggregatibacter (Actinobacillus) actinomycetemcomitans. Infect Immun 75, 4211-4218.
Sharma NC, Galustians HJ, Qaqish J, Charles CH, Vincent JW, and McGuire JA. (2003). Antiplaque and antigingivitis effectiveness of a hexetidine mouthwash. J Clin Periodontol 30, 590-594.

Sharma S, Khan IA, Ali I, et al. (2009). Evaluation of the antimicrobial, antioxidant, and anti-inflammatory activities of hydroxychavicol for its potential use as an oral care agent. Antimicrob Agents Chemother 53, 216-222.

Smith D J, Akita H, King WF, and Taubman MA. (1994). Purification and antigenicity of a novel glucan-binding protein of Streptococcus mutans. Infect Immun 62, 2545-2552.

Suntharalingam P, and Cvitkovitch DG. (2005). Quorum sensing in streptococcal biofilm formation. Trends Microbiol 13, 3-6.

Takahashi N. (2003). Acid-neutralizing activity during amino acid fermentation by Porphyromonas gingivalis, Prevotella intermedia and Fusobacterium nucleatum. Oral Microbiol Immunol 18:109-113.

Tsumori H, and Kuramitsu H. (1997). The role of the Streptococcus mutans glucosyltransferases in the sucrose-dependent attachment to smooth surfaces: Essential role of the gtfC enzyme. Oral Microbiol Immunol 12, 274-280.

Waaler SM, and Rölla G. (1980). Plaque inhibition effect of combinations of chlorhexidine with metal ions zinc and tin. Acta Odont Scand 38: 213-217.

Wennström J, and Lindhe J. (1979). Effect of hydrogen peroxide on developing plaque and gingivitis in man. J Clin Periodontol 6, 115-130.

Whitmore SE, and Lamont RJ. (2014). Oral bacteria and cancer. PLoS Pathog 10, e1003933.

Yanti, Rukayadi Y, Kim KH, and Hwang JK. (2008). In vitro anti-biofilm activity of macelignan isolated from Myristica fragrans Houtt. against oral primary colonizer bacteria. Phytother Res 22, 308-312.

Yanti, Rukayadi Y, Lee KH, and Hwang JK. (2009). Activity of panduratin A isolated from Kaempferia pandurata Roxb. against multi-species oral biofilms in vitro. J Oral Sci 51, 87-95.

Yeung MK. (1999). Molecular and genetic analyses of Actinomyces spp. Crit Rev Oral Biol Med 10, 120-138.

Zeidán-Chuliá F, Gursoy M, de Oliveira BH, et al. (2014). Focused microarray analysis of apoptosis in periodontitis and its potential pharmacological targeting by carvacrol. Arch Oral Biol 59, 461-469.

Address correspondence to: Professor Herman O. Sintim Department of Chemistry Purdue University 560 Oval Drive West Lafayette, ID 47907-2084

E-mail: hsintim@purdue.edu 